\title{
Predictors of Cyberloafing among Preservice Information Technology Teachers
}

\author{
Ozcan Ozgur Dursun \\ Anadolu University, Turkey \\ Onur Donmez \\ Ege University, Turkey \\ Yavuz Akbulut \\ Anadolu University, Turkey
}

\begin{abstract}
The current mixed-method study investigated the extent of involvement in cyberloafing within classroom settings among preservice information technology teachers. Thirteen state universities were picked randomly from hierarchical clusters, which were determined according to the national university rankings. Then, a recent five-factor cyberloafing scale was administered to 1856 participants in these universities to collect the quantitative data. An open-ended survey was also administered to two volunteers from each university $(n: 26)$ to address their rationale for cyberloafing. Parametric analyses on cyberloafing scores were conducted through considering background variables including gender, university, grade level, grade point average, socioeconomic status, ownership of mobile devices and online social networking habits. The qualitative data were processed through descriptive content analysis, which was confirmed by an independent scholar. Findings revealed that males surpassed females in terms of three cyberloafing types (i.e., shopping, accessing online content, and gaming). Significant differences were observed in terms of university and grade level. The relationship between the grade point average and cyberloafing was negative and statistically significant. Socioeconomic status, ownership of mobile devices and social network use predicted cyberloafing behavior. Finally, qualitative data from openended questions revealed student- and instructor-related rationales for cyberloafing.
\end{abstract}

Keywords: Cyberloafing; Cyberslacking; Cyberdeviancy; Teacher education; Media in education

\section{Introduction}

Information and Communication Technologies (ICTs) are getting pervasive in our daily lives. Their wide-scale acceptance is also facilitated through popular utilities for communication (e.g., video calls and e-mail), entertainment (e.g., digital videos and games) and daily tasks (e.g., word processors and payment orders) (Venkatesh, Thong \& Xu, 2012). On the other hand, these utilities may also cause problems like misuse, overuse and addiction.

Frequent and even excessive access to emerging technologies may complicate our lives, interfere with daily activities and reduce productivity. Cyberloafing or cyberslacking is among such counterproductive behaviors which was formerly defined as "employee's use of 
companies' internet access for personal purposes during work hours" (Lim, 2002, p. 675). That is, it has been regarded as a counterproductive and deviant behavior involving employees' abuse of companies' internet access (Philips \& Reddie, 2007, Ugrin, Pearson \& Odom, 2008; Weatherbee, 2010).

While cyberloafing was initially a subject of business and management studies, recent widescale technology integration endeavors and personal mobile devices brought cyberloafing into the current educational research agenda (Ragan, Jennings, Massey \& Doolittle, 2014). In fact, educators were fast to recognize these devices' potential to divert learner attention from the classroom activities (Gerow, Galluch \& Thatcher, 2010). Several studies investigated cyberloafing in educational contexts and underlined that classroom cyberloafing occurrences were in the rise (Akbulut, Dursun, Donmez \& Sahin, 2016; Arabaci, 2017; Karaoglan-Yilmaz, Yılmaz, Oztürk, Sezer \& Karademir, 2015; Taneja, Fiore \& Fischer, 2015; Zoghbi-Manrique deLara, 2012). Perceived as a counterproductive deviant behavior in the workplace, cyberloafing in the classroom is also expected to result in reduced learner attention and lower academic achievement. The following section summarizes the literature review pertaining to reasons and correlates of cyberloafing across different empirical studies.

\section{Literature Review}

Convenient access to emerging interactive technologies offers hundreds of new utilities, which makes employees more prone to deviant technology behaviors. Despite its well-documented prevalence, implications pertaining to cyberloafing has been a controversial topic. Thus, researchers need to address cyberloafing with composure. Some cyberloafing types can even be considered as a facilitator of employee's self-development and relaxation. In this regard, Blanchard and Henle (2008) classified employee cyberloafing as either minor or serious. Minor ones involved common communication (e.g., personal e-mails) and internet surfing (e.g., news, sports sites) that are generally tolerated at work. On the other hand, serious cyberloafing referred to long lasting (e.g., online games), potentially illegal (e.g., adult sites, online gambling) and abusive cyberloafing forms (e.g., excessive music/video downloading). Since these misbehaviors required more cognitive effort and time, they were considered more distractive compared to minor cyberloafing behaviors.

Developments in Internet technologies brought about transformations to cyberloafing phenomenon. For instance, recent definitions included personal use of the internet and mobile devices (Vitak, Crouse \& LaRose, 2011) and social media (Akbulut et al., 2016). Such definitions reflect the transformative nature of cyberloafing. That is, today's emerging communication technologies have already provided us with opportunities beyond surfing and e-mailing, which were considered as basic cyberloafing types in highly-cited works (e.g., Blanchard \& Henle, 2008).

Cyberloafing is expected to correlate with several demographic, social and psychological variables which have been justified through theories of human behavior. The Theory of Reasoned Action (TRA) and the Theory of Planned Behavior (TPB) are frequently cited ones, which argue that probability of a particular behavior is determined by individuals' behavioral intention (Fishbein, 1979; Vallerand, Deshais, Cuerrier, Pelletier \& Mongeau, 1992). The TRA suggests that subjective norms and attitudes toward the behavior are predictors of the behavioral intention. These variables are further predicted by personal beliefs and motivation regarding the outcomes of a particular behavior (Ajzen, 1991). The TPB is derived from the TRA 
through integrating the behavioral control into the theory, which is individuals' perceptions regarding their efficacy and contextual convenience of exercising that particular behavior (Fishbein \& Ajzen, 1975; Taylor \& Todd, 1995).

Insights from TPB and TRA suggest that cyberloafing should be investigated holistically within a range of attitudes, norms, and perceptions, along with motivators and personal beliefs regarding the behavior. For instance, Liberman, Seidman, McKenna and Buffardi (2011) reported that attitudes towards and participation in non-Internet loafing were positively correlated with cyberloafing behaviors. Similarly, Lim (2002) maintains that perceived organizational justice is a predictor of subjective norms, which is a proven determinant of employee cyberloafing. Besides, social context, organizational characteristics, and social pressure significantly correlated with employee cyberloafing (Blanchard \& Henle, 2008; Galluch \& Thatcher, 2011; Restubog, Garcia, Toledano \& Amarnani, 2011). These studies suggest that many variables with the potential to shape social norms are valuable for cyberloafing studies.

Studies with TPB or TRA frameworks reveal that there are positive relationships between habits, attitudes, and intentions (Aarts \& Dijksterhuis, 2000; Beck \& Ajzen, 1991). That is, habitual behaviors are more likely to be activated automatically. In this regard, the number of frequentlyused internet applications (Andreassen, Torsheim \& Pallesen, 2014; Baturay \& Toker, 2015) and the amount of time spent within social networks (Baturay \& Toker, 2015; Chou \& Hsiao, 2000; Karaoglan-Yilmaz et al., 2015) are regarded as significant predictors of cyberloafing. On the other hand, cyberloafing habits are basically dependent upon available technologies. Thus, it is plausible to consider variables regarding technology access and use within a cyberloafing framework (Baturay \& Toker, 2015). Similarly, socio-economic status was shown to predict cyberloafing (Akbulut, Donmez \& Dursun, 2017), which is a critical facilitator of access to technology. Therefore, in addition to technology use habits, mobile technology ownership and socio-economic status were considered as potential predictors in the current study as well.

To investigate the rationale for involvement in cyberloafing, additional theoretical frameworks could be useful as well. For instance, the Goal-Setting Theory (GST), which is based on Social Cognitive Theory (Locke \& Latham, 2004), maintains that personal, social and contextual variables determine personal goals and self-control. Self-control is individual's desire to conform social norms (Ugrin et al., 2008). Since cyberloafing is considered a deviant behavior from the social norms, it is plausible to consider the role of self-control in investigating the phenomenon. In line with the self-control explanations, the literature on motivation may constitute a significant justification for the behavior. Motivation can be either intrinsic or extrinsic. While the intrinsic one involves internal rewards such as enjoyment, the extrinsic one involves extraneous rewards such as course grades. Since cyberloafing has both internal and external motivators, it is plausible to investigate motivating factors regarding the behavior. In addition, to discuss cyberloafing in instructional settings, the ARCS-V motivation model looks plausible as it covers the relevance of instructional practices along with learners' attention, confidence, satisfaction, and volition on the task (Keller, 1987, 2016). In brief, we expect that both the GST and ARCS-V explanations may provide us with a resourceful perspective while interpreting predictors of the behavior.

Since cyberloafing is a technology-centric phenomenon, the role of gender must be considered (Venkatesh et al., 2012). Men tend to spend more time on personal-interest activities than women (Bianchi, Milkie, Sayer \& Robinson, 2000). Accordingly, several studies investigated the role of gender where male participants surpassed females in cyberloafing scores (Askew, 2012; Baturay \& Toker, 2015; Lim \& Chen, 2012). However, recent studies reveal that gender 
differences may vary according to the type and characteristics of the cyberloafing behavior (Akbulut et al., 2016, 2017).

Scholars who investigated cyberloafing in educational settings further considered grade level and academic achievement as potential predictors. Several research documented that cyberloafing correlated negatively with classroom learning (Ravizza, Hambrick \& Fenn, 2014) and academic achievement (Arabaci, 2017; Junco \& Cotten, 2012). For instance, a recent experiment revealed that online messaging during an instructional activity interferes with learning gains (Dindar \& Akbulut, 2016). In addition to the relationship with achievement, Baturay and Toker (2015) reported that grade level was a significant predictor of cyberloafing where students at lower grades had less cyberloafing frequency compared to those in higher grades. Therefore, both grade level and grade point average (GPA) were considered within the scope of the current study.

The current review of the literature revealed a wide repertoire of variables related to cyberloafing. Some of these variables are generic rather than field-specific, which can be used to explain the phenomenon within a wide range of research contexts. As the classroom has its unique dynamics, it is plausible to choose an ambitious path to investigate classroom-specific correlates of cyberloafing. In this regard, the current study considered field-specific variables in addition to generic ones to investigate the construct in depth. Furthermore, a qualitative inquiry was realized so that the rationale for involvement in cyberloafing can be explored through students' eyes.

The target population in the current study were preservice information technology (IT) teachers. They represented a rich resource to investigate cyberloafing as they can be considered as techsavvy undergraduate students. In addition to using technology in their current curriculum, they are supposed to work within technology-rich instructional environments in their future careers. Thus, cyberloafing behaviors of such a digitally competent population may inform further scholars regarding the prevalence and predictors of the behavior.

In line with the current theoretical framework, following research questions were addressed in the current study:

1. What is the extent of involvement in different cyberloafing types across preservice information technology teachers?

2. Does the extent of involvement in cyberloafing behaviors change in accordance with the proposed background variables in the literature? (i.e., gender, university, grade level, grade point average, socio-economic status, access to and experience of information technologies)

3. What are participants' reasons to justify cyberloafing behaviors?

\section{Methods}

\section{Research Model}

The current mixed-method study involved quantitative data to explore the prevalence of cyberloafing among preservice information technology teachers. Then, qualitative data from an open-ended survey were used to explore participants' rationale for their involvement in 
cyberloafing. Thus, the research design had a sequential-explanatory nature (Creswell, 2008). Qualitative and quantitative data were used to address related concepts (i.e., extent and reasons of cyberloafing), and their relationship was discussed while interpreting the data.

Studying the extent of involvement in cyberloafing required a descriptive methodology. Relationships among continuous variables required correlational methods whereas comparisons with regard to categorical variables required causal-comparative techniques (Creswell, 2008; Fraenkel, Wallen \& Hyun, 2011). Finally, responses to the open-ended survey were explored through descriptive content analysis. The research steps were approved by the institutional review board and financially supported by a university research fund.

\section{Participants}

The target population consisted of 9618 preservice information technology teachers at 46 computer education departments at Turkish state universities. Since accessing the whole population was not feasible, sampling was conducted. A confidence interval of three and a confidence level of 99\% required a sample size of 1551 (Bartlett, Kotrlik \& Higgins, 2001). Since the response rate could be a potential threat, questionnaires were sent to 3043 participants at 13 state universities. These universities were picked randomly from 13 hierarchical clusters that were prepared according to national university rankings. Of all participants, 1856 (60.99\%) responded to the data collection tool. The distribution of genders was close. That is, there were 975 males (52.5\%) and 881 females (47.5\%).

All grade levels were represented in the dataset. The sample sizes of freshman ( $f: 420 ; 22.6 \%)$, sophomore ( $f: 422 ; 22.7 \%)$, junior $(f: 441 ; 23.8 \%)$ and senior groups $(f: 573 ; 30.9 \%)$ were close to each other. Of all participants, $1626(87.6 \%)$ had laptops, $1543(83.1 \%)$ had smart phones and $304(16.4 \%)$ had tablet PCs. Popular online applications preferred by the sample was Facebook (f: 1729; 93.2\%), YouTube (f: 1673; 90.1\%), WhatsApp (f: 1538; 82.9\%); Instagram (f: $1039 ; 56 \%)$, Twitter (f: 1001; 53.9\%), Wiki (f: 524; 28.2\%), Foursquare (f: 484; $26.1 \%)$, Vine (f: $384 ; 20.7 \%)$ and Linkedln (f: 178; 9.6\%).

In addition, two students from each sample ( $n: 26)$ responded to the open-ended survey. As they represented both undergraduate student and preservice teacher samples, their perceptions regarding the educational implementations of cyberloafing can be quite valuable to investigate the construct in depth.

\section{Cyberloafing Scale}

The five-factor cyberloafing scale of Akbulut et al. (2016) was used to address the frequency of cyberloafing behaviors during lectures. The scale was followed by a personal information form to address background variables of the study. Following the scale administration, two participants from each university were asked to respond to an additional open-ended survey investigating their rationales for cyberloafing behaviors.

The cyberloafing scale addressed the frequency of 30 cyberloafing behaviors which ranged from 1 (never) to 5 (a great extent). Factors of the scale were sharing (9 items such as posting content, chatting, leaving comments), shopping (7 items such as online shopping, auctioning, banking), real-time updating ( 5 items such as tweeting, retweeting), accessing online content ( 5 items such 
as downloading music, videos and applications) and gaming/gambling (4 items such as betting online, gaming online). The original scale was developed with 471 university students, and confirmed with 215 undergraduates and 515 social network users. The explained variance was $70.44 \%$ for the initial sample, $67.05 \%$ for the first confirmation, and $52.31 \%$ for the second confirmation. The explained variance for the current study was $59 \%$, which was ideal (Henson \& Roberts, 2006). Cronbach's alpha coefficients were high for the total scale (0.95) and individual factors as follows: Sharing (0.93), shopping (0.87), real-time updating (0.93), accessing online content (0.94) and gaming/gambling (0.80).

\section{Data Analysis}

The quantitative data were analyzed through parametric tests, which were conducted with IBM SPSS Statistics 24.0. The data were screened for test assumptions. Pearson correlations and multiple regression were used to assess relationships, whereas t-tests and analyses of variance were used for comparison analyses. Whenever multiple comparisons were realized, Bonferroni Adjustment was considered to reduce the likelihood of committing a Type I error (Huck, 2012). That is, the probability value was divided by the number of tests. Eta squared or partial eta squared values were provided for statistically significant results.

The qualitative data, on the other hand, was analyzed through descriptive content analysis. Individual themes and categories were examined by an independent scholar to sustain concordance between the researchers. In all themes and categories the concordance values between researchers were above $80 \%$. Sample quotations from different participants were provided for each theme.

\section{Findings}

Findings with regard to prevalence of each cyberloafing type revealed that accessing online content was the most frequent cyberloafing type (M: 3.04, SD: 1.15) followed by sharing ( $M$ : 2.89, SD: 0.91), real-time updating ( $M: 2.42, S D: 1.33)$, shopping ( $M: 2.2, S D: 0.94)$ and gaming/gambling ( $M: 2.1, S D: 1.12$ ). One-way repeated measures ANOVA followed by multiple comparisons with Bonferroni suggested that the extent of each cyberloafing behavior was significantly different from one another with a large effect size $\left(F_{4,7420}=664.09 ; p<0.001 ;\right.$ partial eta squared $=0.264$ ). Investigation of each cyberloafing type with regard to background variables was realized in subsequent sections.

\section{Gender}

In order to compare genders with regard to cyberloafing averages, independent-samples t-tests were used. Skewness and kurtosis values were between -2 and +2 , so the normal distribution assumption was met (George \& Mallery, 2010). Descriptive statistics along with parametric test results are summarized in Table 1. Males surpassed females with regard to overall cyberloafing scores. Individual comparisons were interpreted after the Bonferroni Adjustment ( $p=(0.05 / 5)$ $=0.01$ ). After the Bonferroni adjustment, comparisons revealed that males had significantly higher scores in terms of shopping, accessing online content and gaming/gambling. On the other hand, the differences in terms of sharing and real-time updating were not significant. The effect size was high for gaming/gambling and small for other significant results. 
Table 1. Summary of Independent-Samples t-Test with Regard to Gender

\begin{tabular}{lcccccccc}
\hline Variable & Gender & $\mathrm{N}$ & Mean & $\mathrm{SD}$ & $\mathrm{t}$ & $\mathrm{df}$ & $\mathrm{p}$ & $\eta^{2}$ \\
\hline Overall & Female & 881 & 2.397 & .795 & -8.498 & 1854 & $<.001$ & .037 \\
& Male & 975 & 2.723 & .852 & & & & .001 \\
\hline Sharing & Female & 881 & 2.856 & .933 & -1.392 & 1854 & .164 & .001 \\
& Male & 975 & 2.914 & .885 & & & & \\
\hline Shopping & Female & 881 & 1.969 & .841 & -10.353 & 1854 & $<.001$ & .055 \\
& Male & 975 & 2.407 & .969 & & & & \\
\hline Real-time updating & Female & 881 & 2.373 & 1.142 & -1.691 & 1854 & .091 & .002 \\
& Male & 975 & 2.462 & 1.124 & & & & .031 \\
\hline Accessing online & Female & 881 & 2.823 & 1.112 & -7.715 & 1854 & $<.001$ & .031 \\
content & Male & 975 & 3.229 & 1.153 & & & & .170 \\
\hline Gaming / Gambling & Female & 881 & 1.616 & .845 & -19.514 & 1854 & $<.001$ & \\
& Male & 975 & 2.539 & 1.151 & & & &
\end{tabular}

\section{University}

One-way between-groups ANOVA was used to compare universities. Data suggested acceptable skewness and kurtosis coefficients to conduct further parametric analyses. Descriptive statistics are summarized in Table 2. The ANOVA revealed that universities differed with regard to cyberloafing scores $\left(F_{12,1843}=9.064 ; p<0.001\right.$; eta squared $\left.=0.056\right)$. In order to see the source of this difference, Tamhane Test was conducted as the equal variance assumption was not met, and summarized in Table 3. More specifically, mean differences are provided in table cells and significant differences were marked with an asterisk.

Table 2. Descriptive Statistics Pertaining to Each University

\begin{tabular}{llllll}
\hline University & $\mathrm{n}$ & Mean & SD & Skewness & Kurtosis \\
\hline Boğaziçi & 106 & 2.000 & 0.700 & 0.830 & -0.120 \\
Balıkesir & 176 & 2.801 & 0.848 & -0.325 & -0.481 \\
Abant İzzet Baysal & 103 & 2.457 & 0.733 & -0.255 & -0.892 \\
Ege & 126 & 2.424 & 0.895 & 0.069 & -1.195 \\
Gazi Osman Paşa & 145 & 2.673 & 0.797 & -0.236 & -0.372 \\
KTU & 171 & 2.758 & 0.795 & -0.090 & -0.059 \\
Dokuz Eylül & 113 & 2.706 & 0.784 & -0.310 & -0.409 \\
Siirt & 79 & 2.657 & 0.710 & 0.036 & -0.196 \\
Sakarya & 158 & 2.733 & 0.891 & -0.115 & -0.837 \\
Mehmet Akif Ersoy & 108 & 2.264 & 0.859 & 0.203 & -0.988 \\
Çanakkale 18 Mart & 228 & 2.546 & 0.907 & 0.095 & -0.869 \\
Afyon Kocatepe & 156 & 2.509 & 0.734 & -0.259 & -0.663 \\
Fırat & 187 & 2.563 & 0.822 & 0.212 & -0.244 \\
\hline
\end{tabular}

The post-hoc involved 78 comparisons. Repeating this analysis for each cyberloafing type was considered redundant since it required 390 additional comparisons. Besides, this inflates the chance of conducting Type I error. Overall differences across universities were consistent for each cyberloafing type with similar effect size indices. That is, universities differed from each other significantly in terms of sharing $\left(F_{12,1843}=9.967 ; p<0.001\right.$; partial eta squared $\left.=0.061\right)$, shopping $\left(F_{12,1843}=5.630 ; p<0.001\right.$; partial eta squared $\left.=0.035\right)$, real-time updating $\left(F_{12,1843}=5.889\right.$; $p<0.001$; partial eta squared $=0.037)$, accessing online content $\left(F_{12,1843}=8.255 ; p<0.001 ;\right.$ partial 
eta squared $=0.051)$ and gaming/gambling $\left(F_{12,1843}=4.085 ; p<0.001 ;\right.$ partial eta squared $\left.=0.026\right)$. Figure 1 summarized the differences across universities with regard to each cyberloafing type. Finally, the extent of cyberloafing and the national rankings of each university were not correlated significantly (Kendall's tau_ $b=0.051 ; p=0.807$ ).

Table 3. Summary of Multiple Comparisons across Universities

\begin{tabular}{|c|c|c|c|c|c|c|c|c|c|c|c|c|}
\hline & 2 & 3 & 4 & 5 & 6 & 7 & 8 & 9 & 10 & 11 & 12 & 13 \\
\hline Boğaziçi (1) & $-.80^{*}$ & $-.46^{*}$ & -.42 & $-.67^{*}$ & $-.76^{*}$ & $-.71^{*}$ & $-.66^{*}$ & $-.73^{*}$ & -.26 & $-.55^{*}$ & $-.51^{*}$ & $-.56^{*}$ \\
\hline Balıkesir (2) & & .34 & .38 & .13 & .04 & .10 & .14 & .07 & $.54^{*}$ & .26 & .29 & .24 \\
\hline $\begin{array}{l}\text { Abant İzzet } \\
\text { Baysal (3) }\end{array}$ & & & .03 & -.22 & -.30 & -.25 & -.20 & -.28 & .19 & -.09 & -.05 & -.11 \\
\hline Ege (4) & & & & -.25 & -.33 & -.28 & -.23 & -.31 & .16 & -.12 & -.09 & -.14 \\
\hline $\begin{array}{l}\text { Gazi Osman } \\
\text { Paşa (5) }\end{array}$ & & & & & -.09 & -.03 & .02 & -.06 & .41 & .13 & .16 & .11 \\
\hline KTU (6) & & & & & & .05 & .10 & .03 & $.5^{*}$ & .21 & .25 & .20 \\
\hline Dokuz Eylül & & & & & & & .05 & -.03 & .44 & .16 & .20 & .14 \\
\hline Siirt (8) & & & & & & & & -.08 & .39 & .11 & .15 & .09 \\
\hline Sakarya (9) & & & & & & & & & $.47^{*}$ & .19 & .22 & .17 \\
\hline $\begin{array}{l}\text { Mehmet Akif } \\
\text { (10) }\end{array}$ & Ersoy & & & & & & & & & -.28 & -.24 & -.30 \\
\hline $\begin{array}{l}\text { Çanakkale } 18 \\
\text { (11) }\end{array}$ & Mart & & & & & & & & & & .04 & -.02 \\
\hline $\begin{array}{ll}\text { Afyon } & \text { Ko } \\
(12) & \end{array}$ & catepe & & & & & & & & & & & -.05 \\
\hline Firat (13) & & & & & & & & & & & & \\
\hline
\end{tabular}

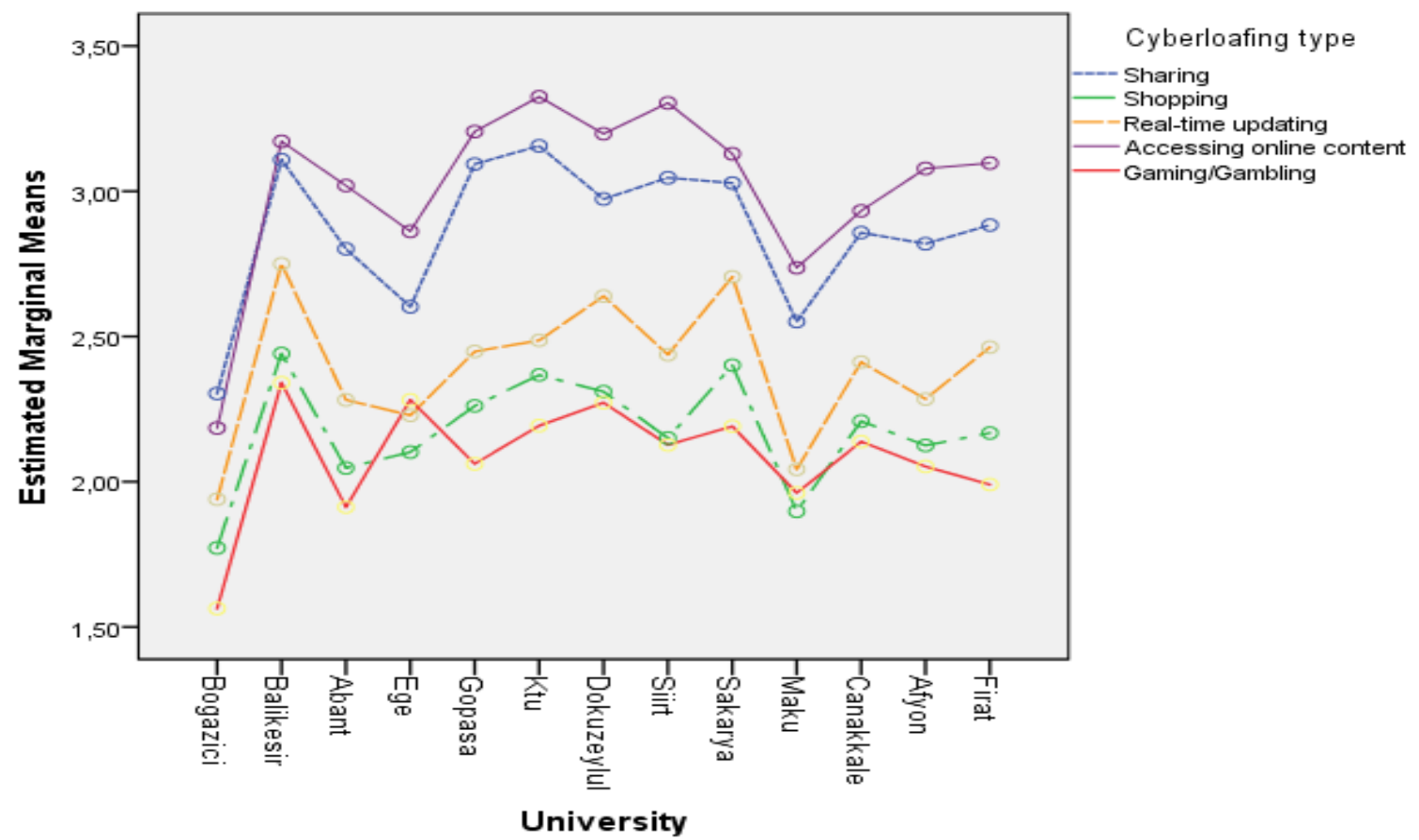

Figure 1. Cyberloafing Types with Regard to University 


\section{Grade Level}

One-way between-groups ANOVA was conducted to compare participants with regard to their grade levels. Normal distribution assumptions were met. The means of freshman ( $M: 4.99, S D$ : $0.91)$, sophomore $(M: 4.99, S D: 0.91)$, junior $(M: 4.99, S D: 0.91)$ and senior groups ( $M: 4.99, S D$ : $0.91)$ were similar to each other $\left(F_{3,1852}=1.789 ; p=0.147\right)$. Comparisons of individual cyberloafing types revealed that grade level differences existed in terms of sharing $\left(F_{3,1852}=5.015 ; p=0.002\right.$; partial eta squared $=0.008)$ and shopping $\left(F_{3,1852}=7.320 ; p<0.001 ;\right.$ partial eta squared $\left.=0.012\right)$. On the other hand, differences were not significant in terms of real-time updating $\left(F_{3,1852}=0.484\right.$; $p=0.69)$; accessing online content $\left(F_{3,1852}=1.44 ; p=0.23\right)$ and gaming/gambling $\left(F_{3,1852}=2.60\right.$; $p=0.051)$. Tamhane test was used to compare grade levels with regard to sharing and shopping. Juniors ( $M: 2.25, S D: 0.94)$ and seniors ( $M: 2.30, S D: 0.97)$ surpassed freshman (M: 2.04, SD: $0.93)$ in terms of shopping. Finally, juniors ( $M: 3.00, S D: 0.89)$ surpassed freshman ( $M: 2.79, S D$ : $0.97)$ in terms of sharing $(p<0.01)$. Note that effect size indices were small.

\section{Grade Point Average (GPA)}

Pearson Product-Moment Correlation was used to investigate the relationship between scores of individual cyberloafing types and GPA. A negative and significant correlation between overall cyberloafing and GPA was observed $(r=-.049 ; p<.05)$. However, this was a small coefficient, which explained only $2 \%$ of the total variance. Individual analyses revealed that the relationships with sharing $(r=0.008)$, shopping $(r=-0.041)$ and real-time updating $(r=-0.017)$ were not significant. On the other hand, the relationships with accessing online content $(r=-0.048 ; p<0.05)$ and gaming/gambling $(r=-0.152 ; p<0.001)$ were significant, which explained $2.3 \%$ and $2.3 \%$ of the variance respectively. Since the explained variance indices were not strong, these coefficients could be attributed to the large sample size. On the other hand, the consistent negative direction of the relationship is worth discussing.

\section{Socio-economic Status}

The relationship between socio-economic status and cyberloafing variables was investigated through Pearson correlation coefficients again. Positive relationships between socio-economic status and overall cyberloafing scores $(r=0.077 ; p<0.001)$, sharing $(r=0.062 ; p<0.001)$, shopping $(r=0.105 ; p<0.001)$ and real-time updating $(r=0.091 ; p<0.001)$ were observed whereas the relationships with accessing online content $(r=0.088)$ and gaming $(r=0.042)$ were not significant. Coefficients and explained variances were too small, but found statistically significant probably due to large sample size.

\section{Access to Mobile Devices}

After the normal distribution assumptions were met, participants who had laptops, tablet PCs and smart phones were compared with those who did not. Having a laptop did not have an impact on cyberloafing averages $\left(\mathrm{t}_{1854}=.355 ; p=0.722\right)$. Participants who had a tablet PC ( $M: 2.76$, $S D: 0.9)$ had significantly higher scores than those who did not $(M: 2.53, S D: 0.83)\left(t_{1854}=4.296\right.$; $p<0.001$; eta squared $=0.01$ ). Finally, participants who had a smart phone (M: $2.59, S D: 0.86)$ had significantly higher scores than those who did not ( $M: 2.47, S D: 0.76)\left(t_{1854}=2.383 ; p<0.001 ;\right.$ eta squared $=0.003$ ). 


\section{Online Social Networking Habits}

The relationship between cyberloafing averages and the number of online utilities used by participants was examined through correlation coefficients. Positive relationships were observed in terms of both overall cyberloafing scores $(r=0.206 ; p<0.001)$ and individual factors. That is, sharing $(r=0.159 ; p<0.001)$, shopping $(r=0.196 ; p<0.001)$, real-time updating $(r=0.250$; $p<0.001)$, accessing online content $(r=0.083 ; p<0.001)$ and gaming/gambling $(r=0.129 ; p<0.001)$ were all correlated with the number of applications used by each participant. Individual contribution of each application was examined through comparing the users and non-users of each application, and through reporting the eta squared values. Twitter had a moderate effect size (0.062) whereas others had small effect size indices. That is, eta squared values of Foursquare (0.058), Vine (0.037), Instagram (0.034), Blog (0.022), forum (0.021), Google+ (0.008), Facebook (0.006), Wiki (0.005), Youtube (0.004), Linkedln (0.003) and WhatsApp (0.002) were relatively small.

Finally, the relationship between cyberloafing and the time spent on different social networks was statistically significant $(r=0.421 ; p<0.001)$. This pattern was observed for all factors. That is, sharing $(r=0.526 ; p<0.001)$, shopping $(r=0.309 ; p<0.001)$, real-time updating $(r=0.311 ; p<0.001)$, accessing online content $(r=0.375 ; p<0.001)$ and gaming/gambling $(r=0.214 ; p<0.001)$ were all correlated with the time spent on social networks. When a stepwise regression was used to explain individual contributions of best predictors, it was observed that five social networks explained $11 \%$ of the variance in cyberloafing behaviors. That is, Twitter $(0.062 \%)$, Foursquare $(0.027 \%)$, Vine $(0.014 \%)$, forum $(0.007 \%)$ and blog $(0.002 \%)$ were the best predictors of cyberloafing $(p<0.001)$.

\section{Reasons for Cyberloafing}

The current scale was useful in understanding the extent of involvement in cyberloafing behaviors. However, it does not reveal participants' rationales for cyberloafing. In this regard, two students from each university were asked about the reasons of their cyberloafing behaviors. Qualitative analyses of the data resulted in a model illustrated in Figure 2. There were various reasons for cyberloafing in the classroom that were somewhat dependent on the context and actors within the classroom. The predominant reasons for cyberloafing were related to instructor's classroom management and teaching skills. Classroom management skills were further elaborated under communication skills and motivational skills, where instructional skills covered instructor's field expertise and methodological repertoire. 


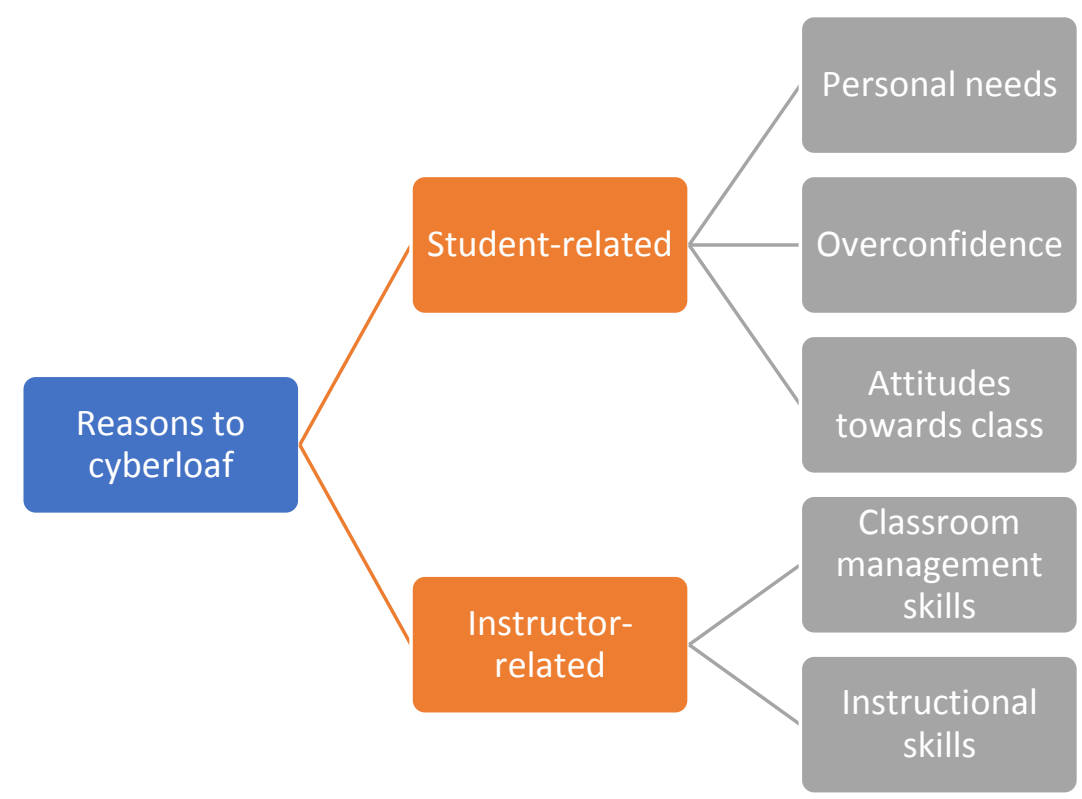

Figure 2. Cyberloafing Reasons

A significant factor about the instructors was their field expertise. Students tended to cyberloaf once they felt that instructors lacked knowledge/expertise regarding the course content. Besides, instructor's methodological repertoire was of importance. Instructors' inability to choose the right instructional method for the subject matter and their tendency to stick with passive lecturing led to student cyberloafing. A participant expressed, passive lecturing hampered them following the course and interfered with the instructor-student interaction: "...the most important factor is instructor's attitude towards the class. If he sticks with the passive lecturing and do not care about class's comprehension students tend to get distant from the class."

Besides, participants emphasized the importance of instructor's classroom management skills. Instructor's attitude towards cyberloafing was perceived as an important factor as one student claimed "...oppressive or over-relaxed classroom management induces these [misbehaviors]". Another student addressed this issue as "Instructor must not leave students alone with PCs and mobile phones."

Participants stressed the importance of motivational elements and communication skills for classroom management. Inability to attract student attention and incompetence to keep student motivation caused cyberloafing. Participants admitted that they looked for novelty. Classes that presented easily-accessible content on the internet demotivated students:

Students lose motivation as there are lots of internet facilities that serve easily accessible theoretical knowledge. Not to mention I can learn from them anytime/anywhere"..."I believe students will be cyberloafing at any instance once the instructor fails to require students take notes, occupy students with classroom activities and stimulate student attention for the subject.

Instructors' verbal communication skills (e.g., feedback, voice, pitch and articulation, and effective communication) were also mentioned in responses. A rather surprising factor was participants' complains about instructors' academic activities. Participants tended to 
demonstrate higher degrees of cyberloafing once the instructors were derelict of their instructional duties due to focusing on scholarly work. These comments leave teacher training programs open to criticisms. While the focus on instructional design skills, comprehensive lectures, and field expertise is strong, courses targeting classroom management and communication skills are somewhat limited. Besides, most of these courses tend to communicate theoretical information rather than practice, which leaves novice teachers almost helpless with student misbehavior.

The second theme of cyberloafing rationales was related to students themselves. Most of these reasons were well-known psychological factors regarding ICT overuse. Participants confessed that they primarily cyberloafed for social networking through which they compensated their socialization and communication needs. Kuss and Griffiths (2011) summarized several motivators (e.g., maintaining offline friendships, social enhancement, maintaining social capital) and personal characteristics (e.g., extroversion, introversion, low self-esteem, low lifesatisfaction, approval addiction) for social media overuse for communication purposes. It is safe to say that seductive nature of social networking disoriented students from classes to easy networking/communication as one student claims "Popularity of social networks and wide range of communication opportunities disorients us from classes. We hardly keep up with the classes". Another student address this issue as "People ubiquitously want to inform others through status updates."

The other side of this communication disorder is the need for keeping up-to-date with others. Fear-of-missing-out (FoMO) is a rather recent phenomenon characterized by constant desire for staying connected with what others doing. Przybylski, Murayama, DeHaan and Gladwell (2013) defined FoMO as pervasive apprehension that others might be having rewarding experiences from which individual is absent. Furthermore, they associated FoMO with lower needsatisfaction, mood and life satisfaction. There were prominent evidences of FoMO in student responses such as "Social networking is becoming an addiction. One urges to check [social networks] frequently". Another example is as follows: "Once you get addicted, you need to check [your social network] over and over again."

Participants expressed self-confidence regarding ICT literacies and multi-tasking abilities as well. A participant claimed that they could keep up with the class and their daily tasks without any performance loss: "In sum, I was able to perform my personal tasks along with the class activities. I tried to fulfil my commitment to the professor's efforts."

However, another participant complained about exaggerated expectations regarding digital natives' fluent ICT use. These expectations are exposing children to threats like technology addiction and leaving them prone to technology-induced risks as exemplified in the following participant remark: "Another reason to [children's] cyberloafing is about our perceptions with children's technology use. We consider them smarter for their fluent technology skills. This belief will leave children prone to technology addiction."

Despite children's fluent interactions with the technology, it is naive to consider them multitasking agents with great ICT skills. Empirical studies reveal that the multitasking advantage attributed to contemporary learners could be a false premise (Kirschner \& van Merrienböer, 2013). Another side effect of this underestimation is cognitive absorption, which is defined as the state of deep involvement with ICTs (Agarwal \& Karahanna, 2000). A participant admitted that they experienced cognitive absorption: "Computer absorbs you. You think, you can complete a task in minutes but in the end you notice time has flown by." 
Similar to the assumptions of the TPB and TRA frameworks, students' attitudes were also influential to cyberloafing in the classroom. Students with negative attitudes towards the lesson or the instructor were keener to cyberloafing. A highly recited reason to cyberloafing was the negative attitudes towards the lesson or the instructor. A participant confessed they experienced personal problems with the instructor and subject matter (e.g., low readiness and inability to comprehend the subject) which led them to cyberloafing. Analyses revealed further reasons for generating negative attitudes towards the class, which were mostly attributed to instructors' attitudes and abilities:

"Students undervalue the classes if the instructor cannot keep the lesson attractive. Furthermore, instructors' attitudes towards students is also of concern. If he ignores or overwhelms students and students cannot get grasp of the subject, they will disorient from the classes."

"Prolonged classes are boring. Besides, some instructors are always lecturing which is also boring. Sooner or later we get distracted and begin texting or playing games."

These comments led us back to revisit instructors' classroom management, course planning, and communication skills. Findings suggested that instructional practices along with students' overconfidence regarding their ICT and multitasking skills aggravated cyberloafing instances. However, these criticisms towards instructors should be considered in line with students' addictive behaviors while explaining cyberloafing instances.

\section{Discussion and Implications}

The current study investigated preservice information technology teachers' cyberloafing profiles through resorting to data from 13 Turkish universities. Several predictors were examined in accordance with the theoretical framework such as gender, university, grade level, grade point average, socio-economic status, access to mobile devices and online social networking habits. Furthermore, two participants from each university were surveyed through open-ended questions to explore their reasons for cyberloafing.

Quantitative data revealed that males reported more cyberloafing instances compared to females. This finding was in line with several studies (Askew, 2012; Karaoglan-Yilmaz et al., 2015). It was viable to attribute this finding to males' perceivably frequent internet use. According to a recent nation-wide report from Turkey, there were more male internet users (64.1\%) than female users (45.9\%) (TUIK, 2016). As a transfer of daily habits, males may be expected to bring their frequent internet use into classes. However, gender differences in terms of internet use and cyberloafing could be controversial as well. For instance, gender differences may vary in accordance with the type of cyberloafing (Akbulut et al., 2017), the nature of the target populations (Akbulut et al., 2016) and the inclusion of the control variables such as social desirability (Akbulut et al., 2017). Accordingly, further analyses regarding gender differences on individual cyberloafing factors revealed that males reported higher scores on shopping, accessing online content, and gaming/gambling. On the other hand, sharing and real-time updating did not differ with regard to gender. These differences could be supported with the findings of Blanchard and Henle (2008) who found that gender and internet skills were significantly correlated with different types of cyberloafing. 
Different universities may provide participants with different learning opportunities. Besides, differences in social norms, perceived organizational justice and administrative measures of each university might have influenced current findings (Blanchard \& Henle, 2008; Lim, 2002). These inferences were further supported through qualitative findings, which suggested that instructors' classroom management and lecturing skills were influential on cyberloafing. However, further data from both students and instructors are needed regarding these unique contextual characteristics to explore the potential predictors better.

Total cyberloafing scores did not significantly change according to grade levels, which seemed to contradict with the findings of Baturay and Toker (2015). On the other hand, further analyses revealed significant differences in terms of sharing and shopping. That is, juniors surpassed freshman on sharing whereas juniors and seniors surpassed freshman on shopping. Baturay and Toker (2015) justified the relationship between cyberloafing and grade level through students' cultivation of confidence, comfort, and familiarity over time. The current study further revealed that such a change in students' cyberloafing behaviors were available only in some cyberloafing types. Thus, in addition to the gender question discussed above, further studies should delve into individual cyberloafing types while considering grade level as a predictor.

Grade point average correlated negatively with cyberloafing, which was in line with Arabaci's (2017) findings. Achievement-oriented individuals might choose to stay out of distractors through exercising more effective self-regulation strategies. Accordingly, Tangney, Baumeister and Boone (2004) reported that self-regulation was positively correlated with academic achievement, adjustment (e.g., higher self-esteem, lower pathologic behaviors) and more optimal emotional responses. Thus, the current finding was consistent with the related literature. In this regard, further studies may include students' grade point averages or further context-specific achievement metrics as a potential correlate of cyberloafing.

Socio-economic status and cyberloafing correlated significantly. Further analyses suggested that socio-economic status correlated positively with sharing, shopping, and real-time updating. However, correlations were not significant for gaming/gambling and accessing online content. Despite recent major technology integration studies, technology access is still determined by socio-economic status (Ching, Basham \& Jang, 2005; Porter \& Donthu, 2006). Hence, it is feasible to expect socio-economic status to facilitate cyberloafing. These inferences were further confirmed through findings on mobile technology access where tablet PC and smartphone ownership were significant predictors of cyberloafing. Such observations were confirmed through qualitative findings as students admitted easy access to technology disoriented them from classes. These interpretations are in line with the contemporary literature. For instance, Karaoglan-Yilmaz et al. (2015) maintained that laboratory settings triggered cyberloafing, which was a facilitating condition among current preservice IT teacher population as well. ICTs' facilitator role was reflected in both qualitative and quantitative findings, which was in line with the contemporary literature regarding the role of facilitating conditions on technology adoption (Venkatesh et al., 2012).

The relationship between cyberloafing and the number of internet utilities was positive as expected (Andreassen et al., 2014; Baturay \& Toker, 2015), which can be explained through the literature on the influence of habits on automated behaviors (Aarts \& Dijksterhuis, 2000; Beck \& Ajzen, 1991). Similarly, the time spent with social networking tools was significantly correlated with cyberloafing (Baturay \& Toker, 2015; Chou \& Hsiao, 2000; Karaoglan-Yilmaz et al., 2015). The number and frequency of social networking tools preferred by the participants underlined the importance of communication affordances offered by these utilities. Parallel with the 
quantitative findings, communication needs occupied a considerable share within comments regarding technology's facilitating role. Social interaction was considered more valuable than academic endeavors by students as indicated in the literature (Wigfield \& Eccles, 2000), which suggested that preferring socialization to academic tasks was sometimes a planned choice of action.

Some participants both accepted their involvement in cyberloafing and resorted to their perceived multitasking advantage as a rationale; however, the empirical literature does not support this advantage (Kirschner \& van Merrienböer, 2013). Multitasking may even interfere with the quality of instructional outcomes (Dindar \& Akbulut, 2016; Fried, 2008; Sana, Weston, \& Cepeda, 2013; Yoruk-Acikel, Turhan, \& Akbulut, 2017). Contrary to empirical evidence, participants reported that they did not miss instructional activities for the sake of online technology use in class. Further reasons for cyberloafing involved the negative attitudes towards the course, instructor or the department, which were expected to correlate with cyberloafing (Liberman et al., 2011). That is, as reflected in the TRA framework, they might have resorted to negative attitudes to justify the rightness of their cyberloafing behaviors. On the other hand, some participants underlined the role of further psychosocial variables such as addiction and cognitive absorption (i.e., deep involvement with ICTs) to explain their cyberloafing behaviors. In brief, findings revealed that many of explanations were in line with the assumptions of the Goal-Setting Theory, which underlined the role of different personal, social, and contextual variables on personal goals and self-control.

A significant practical implication of the current work is the need for the improvement of classroom practices to eliminate cyberloafing behaviors. Instructional methods and classroom management skills of instructors were criticized while justifying cyberloafing. The lack of motivation was the crucial factor mentioned by several participants. Instructors' ineffectiveness in terms of catching students' attention and building satisfaction seemed to correlate with frequent cyberloafing. In this regard, flipping the classroom can help instructors transform the learning experiences. That is, dealing with the theoretical information outside the classroom and realizing practice in class may both increase active participation and decrease cyberloafing instances. Furthermore techno-centric precautions in ICT classes such as screen monitoring or control software, and regulations regarding cell-phone use could be alternative options.

In addition to serving to attention component of the ARCS-V model, relevance of the instructional materials should also be questioned and a link between student purposes and the course objectives should be created (Keller, 2016). As meaningfulness of a task is quite related with cyberloafing (Jia, Jia \& Karau, 2013), such an action can help us eliminate counterproductive ICT use in class. In this regard, alternative interventions to increase instructional effectiveness and decrease irregular ICT use in class should be implemented and reported for further scholars.

\section{Limitations and Recommendations}

Even though the probability of committing a Type I Error was eliminated through conducting Bonferroni Adjustment, some of the statistically significant findings might be due to the large sample size. In the current study, effect size indices were reported after statistically significant findings to evaluate the practical significance. These indices were relatively small for analyses regarding gender, university, grade level, socio-economic status and access to mobile devices. On the other hand, moderate effect sizes pertaining to some social network tools and moderate correlations regarding the time spent for social networking can be taken into account as control 
variables in further studies. Besides, it was observed that access, use and competence were related variables which should be taken into account in further cyberloafing research.

Self-report instruments on sensitive topics may have several limitations such as inconsistent or socially desirable responding (Akbulut, 2015; Akbulut et al., 2017). Therefore, alternative and multiple measures need to be used in cyberloafing research. While the current data was enriched through a qualitative measure, all analyzes were based on self-reports of students. In this regard, in addition to integration of alternative measures, perceptions of instructors need be considered. For instance, instructors might blame contemporary students' learning and technology immersion states rather than their own instructional practices. Thus, focus group interviews involving both parties might be quite plausible to reach a consensus. Such an investigation may further help us to design and test relevant interventions to enrich instructional practices and diminish cyberloafing in class.

As the current scale was validated across different samples in a variety of settings, investigating the prevalence rates and predictors in educational settings may help us understand the unique social norms pertaining to cyberloafing in each setting. While addressing the extent of the behavior, technology use and access patterns can also be considered as they were significant predictors. Finally, significant correlates in the current work may inform potential structural equation models to enrich our understanding of the phenomenon.

\section{Acknowledgements}

We thank Anadolu University Research Fund for financing the current research project (Project ID: 1304E077). We also thank the Editor and three anonymous reviewers for their valuable comments.

\section{References}

Aarts, H. \& Dijksterhuis, A. (2000). Habits as knowledge structures: Automaticity in goaldirected behavior. Journal of Personality and Social Psychology 78(1), 53-63. https://doi.org/10.1037/0022-3514.78.1.53

Agarwal, R. \& Karahanna, E. (2000). Time flies when you're having fun: Cognitive absorption and beliefs about information technology usage, MIS Quarterly, 24(4), 665-694. https://doi.org/10.2307/3250951

Ajzen, I. (1991). The theory of planned behavior. Organizational Behavior and Human Decision Processes, 50(2), 179-211. https://doi.org/10.1016/0749-5978(91)90020-t

Akbulut, Y. (2015). Predictors of inconsistent responding in web surveys. Internet Research, 25(1), 131-147. https://doi.org/10.1108/IntR-01-2014-0017

Akbulut, Y., Dursun, O. O., Donmez, O., \& Sahin, Y. L. (2016). In search of a measure to investigate cyberloafing in educational settings. Computers in Human Behavior, 55, 616625. https://doi.org/10.1016/j.chb.2015.11.002

Akbulut, Y., Donmez, O., \& Dursun, O. O. (2017). Cyberloafing and social desirability bias among students and employees. Computers in Human Behavior, 72, 87-95. https://doi.org/10.1016/j.chb.2017.02.043 
Andreassen, C.S., Torsheim, T., \& Pallesen, S. (2014). Predictors of use of social network sites at work-a specific type of cyberloafing. Journal of Computer-Mediated Communication, 19(4), 906-921. https://doi.org/10.1111/jcc4.12085

Arabaci, i.B. (2017). Investigation of faculty of education students' cyberloafing behaviors in terms of various variables. The Turkish Online Journal of Educational Technology, 16(1), 72-82. Retrieved on 27 November 2017 from http://www.tojet.net/articles/v16i1/1617. pdf

Askew, K.L. (2012). The relationship between cyberloafing and task performance and an examination of the theory of planned behavior as a model of cyberloafing. (Unpublished doctoral dissertation) Graduate School Theses and Dissertations, University of South Florida. Retrieved on 27 November 2017 from http://scholarcommons.usf.edu/cgi/ viewcontent.cgi?article $=5153 \&$ context $=$ etd

Bartlett, J.E., Kotrlik, J.W., \& Higgins, C.C. (2001). Organizational research: Determining appropriate sample size in survey research. Information Technology, Learning and Performance Journal, 19(1), 43-50. Retrieved on 27 November 2017 from http://citeseerx.ist.psu.edu/viewdoc/download?doi=10.1.1.486.8295\&rep=rep1\&type= pdf

Baturay, M.H. \& Toker, S. (2015). An investigation of the impact of demographics on cyberloafing from an educational setting angle. Computers in Human Behavior, 50, 358366. https://doi.org/10.1016/j.chb.2015.03.081

Beck, L. \& Ajzen, I. (1991). Predicting dishonest actions using the theory of planned behavior. Journal of Research in Personality, 25(3), 285-301. https://doi.org/10.1016/00926566(91)90021-h

Bianchi, S.M., Milkie, M.A., Sayer, L.C., \& Robinson, J.P. (2000). Is anyone doing the housework? Trends in the gender division of household labor. Social Forces, 79(1), 191228. https://doi.org/10.1093/sf/79.1.191

Blanchard, A. \& Henle, C. (2008). Correlates of different forms of cyberloafing: The role of norms and external locus of control. Computers in Human Behavior, 24(3), 1067-1084. https://doi.org/10.1016/j.chb.2007.03.008

Ching, C.C., Basham, J.D., \& Jang, E. (2005). The legacy of the digital divide: Gender, socioeconomic status, and early exposure as predictors of full-spectrum technology use among young adults. Urban Education, 40(4), 394-411. https://doi.org/10.1177/ 0042085905276389

Chou, C. \& Hsiao, M.C. (2000). Internet addiction usage, gratification, and pleasure experience: The Taiwan college students' case. Computers \& Education, 35(1), 65-80. https://doi.org/10.1016/s0360-1315(00)00019-1

Creswell, J.W. (2008). Educational research: Planning, conducting, and evaluating quantitative and qualitative research (3rd edition). Upper Saddle River: Pearson.

Dindar, M., \& Akbulut, Y. (2016). Effects of multitasking on retention and topic interest. Learning and Instruction, 41, 94-105. https://doi.org/10.1016/j.learninstruc.2015.10.005

Fishbein, M. (1979). A theory of reasoned action: Some applications and implications. Nebraska Symposium on Motivation, 27, 65-116.

Fishbein, M.A. \& Ajzen, I. (1975). Belief, attitude, intention and behavior: An introduction to theory and research. Reading, MA: Addison-Wesley. 
Fraenkel, J.R., Wallen, N.E., \& Hyun, H.H. (2011). How to design and evaluate research in education (8th edition). New York: McGraw-Hill.

Fried, C.B. (2008). In-class laptop use and its effects on student learning. Computers \& Education, 50(3), 906-914. https://doi.org/10.1016/j.compedu.2006.09.006

Galluch, P. \& Thatcher, J. (2011). Maladaptive vs. faithful use of internet applications in the classroom: An empirical examination. JITTA: Journal of Information Technology Theory and Application, 12(1), 5-21. Retrieved on 27 November 2017 from http://aisel. aisnet.org/jitta/vol12/iss1/2/

George, D. \& Mallery, M. (2010). Using SPSS for Windows step by step: A simple guide and reference. Boston, MA: Allyn \& Bacon.

Gerow, J.E., Galluch, P., \& Thatcher J.B. (2010). To slack or not to slack: Internet usage in the classroom. Journal of Information Technology Theory and Application (JITTA), 11(3), 524. Retrieved on 27 November 2017 from http://aisel.aisnet.org/jitta/vol11/iss3/2/

Henson, R.K. \& Roberts, J.K. (2006). Use of exploratory factor analysis in published research. Educational and Psychological Measurement, 66(3), 393-416. https://doi.org/10.1177/0013164405282485

Huck, S.W. (2012). Reading statistics and research (6th ed.). Boston: Pearson.

Jia, H., Jia, R., \& Karau, S. (2013). Cyberloafing and Personality: The impact of the big five traits and workplace situational factors. Journal of Leadership \& Organizational Studies, 20(3), 358-365. https://doi.org/10.1177/1548051813488208

Junco, R. \& Cotten, S.R. (2012). No A 4 U: The relationship between multitasking and academic performance. Computers \& Education, 59(2), 505-514. https://doi.org/10.1016/j.compedu.2011.12.023

Karaoglan-Yilmaz, F.G., Yılmaz, R., Ozturk, H.T., Sezer, B., \& Karademir, T. (2015). Cyberloafing as a barrier to the successful integration of information and communication technologies into teaching and learning environments. Computers in Human Behavior, 45, 290-298. https://doi.org/10.1016/j.chb.2014.12.023

Keller, J.M. (1987). Development and use of the ARCS model of instructional design. Journal of instructional development, 10(3), 2-10. https://doi.org/10.1007/bf02905780

Keller, J.M. (2016). Motivation, learning, and technology: Applying the ARCS-V Motivation Model. Participatory Educational Research (PER), 3(2), 1-13. https://doi.org/10.17275/per.16.06.3.2

Kirschner, P.A. \& van Merrienböer, J.J.G. (2013). Do learners really know best? Urban legends in education. Educational Psychologist, 48(3), 169-183. https://doi.org/10.1080/00461520.2013.804395

Kuss, D.J. \& Griffiths, M.D. (2011). Online social networking and addiction-a review of the psychological literature. International journal of environmental research and public health, 8(9), 3528-3552. https://doi.org/10.3390/ijerph8093528

Liberman, B., Seidman, G., McKenna, K.Y.A., \& Buffardi, L.E. (2011), Employee job attitudes and organizational characteristics as predictors of cyberloafing. Computers in Human Behavior 27(6), 2192-2199. https://doi.org/10.1016/j.chb.2011.06.015 
Lim, V.K.G. (2002). The IT way of loafing on the job: Cyberloafing, neutralizing and organizational justice. Journal of Organizational Behavior, 23(5), 675-694. https://doi.org/10.1002/job.161

Lim, V.K.G. \& Chen, D.J.Q. (2012). Cyberloafing at the workplace: gain or drain on work? Behaviour \& Information Technology, 31(4), 343-353. https://doi.org/10.1080/01449290903353054

Locke, E.A. \& Latham, G.P. (2004). What should we do about motivation theory? Six recommendations for the twenty-first century. Academy of Management Review, 29(3), 388-403. https://doi.org/10.2307/20159050

Philips, J.G. \& Reddie, L. (2007). Decisional style and self-reported e-mail use in the workplace. Computers in Human Behavior. 23(5), 2414-2428. https://doi.org/10.1016/j.chb.2006.03.016

Porter, C.E. \& Donthu, N. (2006). Using the technology acceptance model to explain how attitudes determine Internet usage: The role of perceived access barriers and demographics. Journal of Business Research, 59(9), 999-1007. https://doi.org/10.1016/j.jbusres.2006.06.003

Przybylski, A.K., Murayama, K., DeHaan, C.R., \& Gladwell, V. (2013). Motivational, emotional, and behavioral correlates of fear of missing out. Computers in Human Behavior, 29(4), 1841-1848. https://doi.org/10.1016/j.chb.2013.02.014

Ragan, E.D., Jennings, S.R., Massey, J.D., \& Doolittle, P.E. (2014). Unregulated use of laptops over time in large lecture classes. Computers \& Education, 78, 78-86. https://doi.org/10.1016/j.compedu.2014.05.002

Ravizza, S.M., Hambrick, D.Z., \& Fenn, K.M. (2014). Non-academic internet use in the classroom is negatively related to classroom learning regardless of intellectual ability. Computers \& Education, 78, 109-114. https://doi.org/10.1016/j.compedu.2014.05.007

Restubog, S.L.D., Garcia, P.R.J.M., Toledano, L.S., \& Amarnani, R.K. (2011). Yielding to (cyber)temptation: Exploring the buffering role of self-control in the relationship between organizational justice and cyberloafing behavior in the workplace. Journal of Research in Personality, 45(2), 247-251. https://doi.org/10.1016/j.jrp.2011.01.006

Sana, F., Weston, T., \& Cepeda, N.J. (2013). Laptop multitasking hinders classroom learning for both users and nearby peers. Computers \& Education, 62, 24-31. https://doi.org/10.1016/j.compedu.2012.10.003

Taneja, A., Fiore, V., \& Fischer, B. (2015). Cyber-slacking in the classroom: Potential for digital distraction in the new age. Computers \& Education, 82, 141-151. https://doi.org/10.1016/j.compedu.2014.11.009

Tangney, J.P., Baumeister, R.F., \& Boone, A.L. (2004). High self-control predicts good adjustment, less pathology, better grades, and interpersonal success. Journal of personality, 72(2), 271-324. https://doi.org/10.1111/j.0022-3506.2004.00263.x

Taylor, S. \& Todd, P.A. (1995). Decomposition and crossover effects in the theory of planned behavior: A study of consumer adoption intentions. International Journal of Research in Marketing, 12(2), 137-156. https://doi.org/10.1016/0167-8116(94)00019-k

TUIK (2016). Information and communication technology (ICT) usage survey on households and individuals. Press Release (18660). Ankara: Turkish Statistical Institute. Retrieved on 17 February 2017 from http://www.turkstat.gov.tr/PreHaberBultenleri.do?id=21779 
Ugrin, J.C., Pearson, J.M., \& Odom, M.D. (2008). Cyber-slacking: self-control, prior behavior and the impact of deterrence measures. Review of Business Information Systems, 12(1), 75- 88. https://doi.org/10.19030/rbis.v12i1.4399

Vallerand, R.J., Deshais, P., Cuerrier, J., Pelletier, L.G., \& Mongeau, C. (1992). Ajzen and Fishbein's theory of reasoned action as applied to moral behavior: A confirmatory analysis. Journal of Personality and Social Psychology, 62(1), 98-109. https://doi.org/10.1037/0022-3514.62.1.98

Venkatesh, V., Thong, J.Y., \& Xu, X. (2012). Consumer acceptance and use of information technology: Extending the Unified Theory of Acceptance and Use of Technology. MIS Quarterly, 36(1), 157-178. Retrieved on 27 November 2017 from https://papers.ssrn. com/sol3/papers.cfm?abstract id $=2002388$

Vitak, J., Crouse, J., \& LaRose, R. (2011). Personal Internet use at work: Understanding cyberslacking. Computers in Human Behavior, 27(5), 1751-1759. https://doi.org/10.1016/j.chb.2011.03.002

Weatherbee, T.G. (2010). Counterproductive use of technology at work: Information \& communications technologies and cyberdeviancy. Human Resource Management Review, 20(1), 35-44. https://doi.org/10.1016/j.hrmr.2009.03.012

Wigfield, A. \& Eccles, J. S. (2000). Expectancy-value theory of achievement motivation. Contemporary Educational Psychology, 25(1), 68-81. https://doi.org/10.1006/ceps.1999.1015

Yoruk-Acikel, B., Turhan, U., \& Akbulut, Y. (2017). Effect of multitasking on simulator sickness and performance in 3D aerodrome control training. Simulation \& Gaming. https://doi.org/10.1177/1046878117750417

Zoghbi Manrique de Lara, P. (2012). Reconsidering the boundaries of the cyberloafing activity: the case of a university. Behaviour \& Information Technology, 31(5), 469-479. https://doi.org/10.1080/0144929x.2010.549511

Correspondence: Yavuz Akbulut, Professor, Department of Educational Sciences, Faculty of Education, Anadolu University, Yunus Emre Campus, Eskisehir, Turkey 